appearance of the articular signs concomitantly with the first elements of the varicella eruption, the involvement of the metatarsophalangeal joints (not previously reported), and the short duration of the symptoms. The Table gives data on the reported cases, including this one, and on 2 additional children with bacterial arthritis complicating varicella. It is interesting that 7 of the 9 children with viral arthritis were girls, including our patient. The age range was between $2 \frac{1}{2}$ years (our patient) and 10 years. In all of the earlier cases, large articulations were involved (6 of them in the knee joint). In 3 children smaller joints were also affected. Our patient was the only one in which only small articulations were affected. The joint symptoms appeared concomitantly or several days after appearance of the eruption. The duration of the articular involvement was between 2 and 15 days. Six of the 9 patients presented with fever. The ESR was normal in 2 children and slightly raised in 4 . In only 3 cases was the WBC $>10.0 \times 10^{9} / 1$.

In most of the patients with chickenpox, the arthritis was probably due to a direct invasion by the varicella virus. The virus was recently isolated from the synovial fluid in one affected patient. ${ }^{3}$ Rarely was the arthritis the result of bacterial invasions; two such cases have been reported. ${ }^{1-2}$ In these patients the origin of the infection was via blood spread from infected varicella skin lesions. ${ }^{1}$

As antimicrobial treatment is urgently indicated in all cases of pyogenic arthritis, it is important to differentiate between a bacterial and nonbacterial process as quickly as possible. Although microscopical examination of synovial fluid aspirated from the affected joint and its culture is the only way to establish the diagnosis with certainty, arthrocentesis is not a completely harmless procedure and may be very difficult to accomplish in small joints, particularly in young children. As the inflammatory articular signs lasted for only 2 to 4 days in most of the cases reported, it seems reasonable that in patients in whom arthrocentesis may be a problem, this procedure should be postponed for 1 or 2 days.

\section{References}

1 Buck R E. Letter: Pyarthrosis of the hip complicating chickenpox. JAMA 1968; 206: 135-6.

2 Sethi A S, Schloff M. Purulent arthritis complicating chickenpox. Clin Pediatr (Phila) 1974; 13: 280.

3 Priest J R, Urick J J, Groth K E, Balfour H H, Jr. Varicella arthritis documented by isolation of virus from joint fluid. J Pediatr 1978; 93: 990-2.

4 Brook I. Varicella arthritis in childhood. Clin Pediatr (Phila) 1977; 16: 1156-7.

5 Ward J R, Bishop B. Varicella arthritis. JAMA 1970; 212 : 1954-6.

- Di Liberti J H, Bartel S J, Humphrey T R, Pang A W. Acute monoarticular arthritis in association with varicella. Clin Pediatr (Phila) 1977; 16: 663-4.

7 Mulhern L N, Friday G A, Perri J A. Arthritis complicating varicella infection. Pediatrics 1971; 48: 827-9.

8 Friedman A, Naveh Y. Polyarthritis associated with chickenpox. Am J Dis Child 1971; 122: 179-80.

Correspondence to Dr I Varsano, Paediatric Day Care and Outpatient Service, Beilinson Medical Centre, Petah Tiqva, Israel.

\title{
Cutaneous polyarteritis nodosa in a young child
}

\section{JULIAN VERBOV}

Royal Liverpool Children's Hospital, Liverpool

SUMMARY A $5 \frac{1}{2}$-year-old girl presented with an acute febrile illness associated with limb and facial swelling, and a skin eruption. She was diagnosed as suffering from cutaneous polyarteritis nodosa. She was told to stay in bed and was given soluble aspirin. Now, more than 3 years later, she is well and symptom-free. The important diagnostic feature of this benign condition, which is distinct from the systemic disease, is the presence of skin nodules showing the histology of a necrotising arteritis at the junction of dermis and subcutaneous tissue.
Polyarteritis nodosa, a rare disease at any age, can be benign and affect only the skin, or it may affect the skin, skeletal muscles, and peripheral nerves. Clinically, cutaneous polyarteritis nodosa presents as painful nodules generally on the lower part of the legs. These nodules are usually associated with livedo reticularis-a physical sign with many causes which signifies capillary and venular stasis in cooled skin, influenced by factors including obstruction or constriction of the small subcutaneous arteries. It is the nodulation rather than the livedo that is the hallmark of the cutaneous disease. In the systemic 
disease, eruptions tend to be nonspecific and include livedo reticularis, erythemas, urticaria, or purpura. Borrie $^{1}$ concluded that about $10 \%$ of all cases of polyarteritis nodosa were benign.

\section{Case report}

A white girl aged 5 years 7 months was admitted to hospital as an emergency on 11 June 1976. She had been off colour and anorexic for 4 days although still attending school, but on the day of admission had developed painful swollen forearms, wrists, left hand, and left foot and had difficulty in walking. There was a history of an asymptomatic rash for a year.

On examination, she was febrile $\left(37.9^{\circ} \mathrm{C}\right)$ and toxic. Face, forearms, wrists, left hand, right knee, and left foot were swollen and a patchy maculopapular erythematous eruption affected not only these areas but others (Fig. 1). Upper limb movement was restricted by pain. There were no abnormal

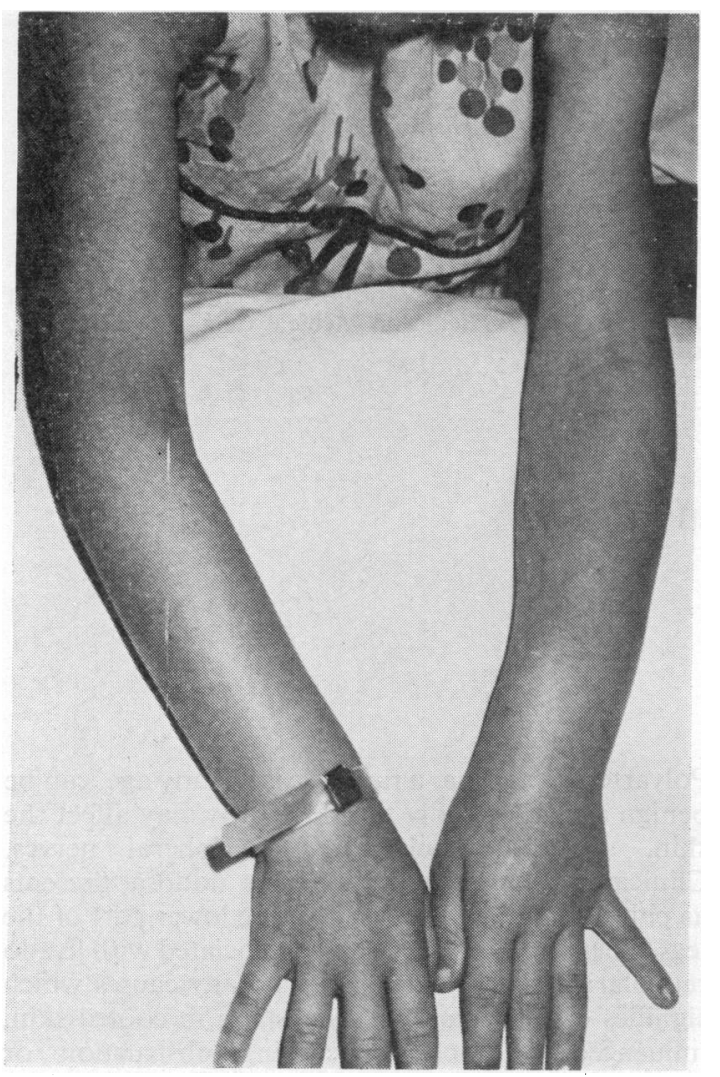

Fig. 1 Swollen forearms, wrists, and dorsum left hand with faint erythema over extensor aspect lower forearms. throat or lung signs, and the cardiovascular system, apart from a regular tachycardia, was normal. Although her blood pressure at admission was recorded as $108 / 90 \mathrm{mmHg}$, all subsequent estimations in hospital and later at outpatient visits have been $90-95 / 60 \mathrm{mmHg}$. No liver or spleen was palpable. Investigations showed a sedimentation rate of $100 \mathrm{~mm}$ in 1st hour, total white cell count 15.0 $\times 10^{9} / 1$ (neutrophils $78 \%$, lymphocytes $14 \%$, monocytes $6 \%$, eosinophils $2 \%$ ), $\mathrm{Hb} 10 \cdot 3 \mathrm{~g} / \mathrm{dl}$. No pathogens were isolated from throat $(11,21,27$ June), nasal swabs, or stools. Normal investigations included midstream urine specimen, blood urea and electrolytes, creatinine clearance, serum creatine kinase and aldolase, Wassermann reaction, liver function tests, RA latex, and viral studies including hepatitis B antigen. No LE cells were present. Antistreptolysin-O (ASO) titre was 900 (normal 0-200) Todd units on 21 June (800 units in July 1976, 1600 units in November 1976, and 800 units in January 1977). Electrocardiogram was normal. $X$-ray of chest was normal and $x$-rays of wrists and left ankle showed no bony change. Right calf muscle biopsy showed normal striated muscle. Skin biopsy from an erythematous area over the dorsal aspect of the left forearm showed a pronounced necrotising vasculitis in the lower dermis consistent with polyarteritis nodosa. She was treated with soluble aspirin $300 \mathrm{mg}$ 4-hourly at first and then in gradually reducing dosage, and told to stay in bed.

As the swelling and illness subsided during the next 2 to 3 weeks the skin showed more obvious nodulation and cyanotic reticulation and in some areas just bruise-like discoloration. She was discharged after 3 weeks in hospital. By the end of July most symptoms had settled, but the right knee was still swollen making walking uncomfortable. Muscle wasting was visible over the upper arms and right thigh. In August she had a bout of swelling for a few days affecting the right knee and left hand. Livedo and nodulation increased and extended during the next few months as her general condition improved (Fig. 2); nodulation was particularly pronounced over the buttocks and above the right ankle. By October she had full joint movement. When examined in May 1977 nodulation and livedo were prominent over the flexor aspect of the lower limbs, and livedo was also visible over the posterior chest. No nodules have been palpable since the end of 1977 and in July 1979 obvious livedo was only visible around the knees and this was slight.

\section{Discussion}

It is not generally recognised that there is a benign form of polyarteritis nodosa in which arteritic 


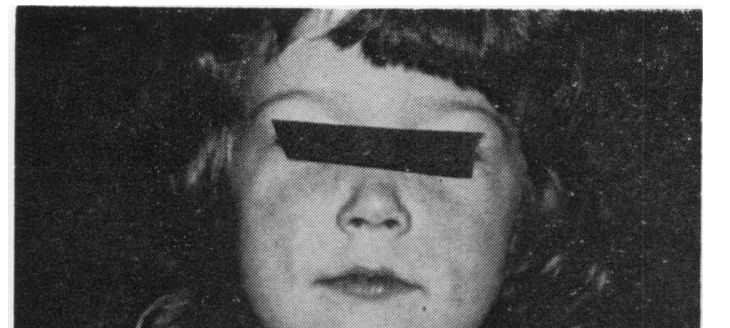

In cutaneous polyarteritis nodosa the cutaneous lesions show a histology typical of polyarteritis nodosa, the disease is not fatal and spontaneous recovery occurs after some years. The small arteries are in the superficial subcutaneous tissue, but lesions may extend into the arterioles of the dermis as well. Small subcutaneous veins may also be affected. Ryan $^{4}$ preferred to include cutaneous polyarteritis nodosa under the term nodular vasculitis. $\mathrm{He}$ considered that venous rather than arterial disease was often the more likely cause, citing a total absence of infarction as being compatible with venous disease.

Systemic corticosteroids may be necessary in some patients but as the prognosis is good, dosage with these or other drugs to achieve complete control is not indicated. ${ }^{5}$

In the skin, firm dermal erythematous or skincoloured nodules $0.5-2 \mathrm{~cm}$ in diameter occur in crops and persist for a few days or a few weeks. They may be symptomless, tender, or extremely painful but they usually resolve spontaneously without scarring although ulceration can occur. ${ }^{6}$ Nodules are particularly common on the lower part of the leg but they can be widespread on the limbs, trunk, and even on the face. Livedo may precede, accompany, or follow the nodules, and nodulation may appear in sites both affected and unaffected by livedo. There may be a myositis associated with the skin lesions; this causes pain and stiffness particularly in the legs, and a peripheral neuritis can be present which occasionally causes permanent deformity. Myositis and single or multiple mononeuritis are relatively short lived and certainly clear before the cutaneous lesions. The child described at no time showed any evidence of neuritis.

Specific cutaneous involvement in systemic polyarteritis nodosa is rare, and when it does occur it is usually with fulminating disease and consists of a rather nonspecific erythematous eruption, the histology showing polyarteritis nodosa. Much more common is an erythematous, urticarial, or purpuric rash which generally occurs in more acute cases and shows a nonspecific histology.?

It seems likely that the rash this child had for about

Fig. 2 Nodulation and livedo over face, right shoulder, and forearms.

lesions affect small vessels in skin, skeletal muscle, and peripheral nerves, but only rarely affect vessels in other tissues. When the condition is around the joints arthritis may be simulated. ${ }^{2}$ Muscle wasting may occur and fever and a raised sedimentation rate are common. Golding ${ }^{3}$ described 3 patients with the condition in whom lesions were confined to the skin or leg muscles. a year before her acute illness was a widespread but patchy livedo reticularis, and it is interesting that with acute facial and limb soft tissue swelling her nodulation and livedo as such were masked, only to appear obvious as swelling subsided and her condition improved.

The aetiology is obscure. Bradford et al. ${ }^{8}$ described 3 children with livedo reticularis with nodulation and considered streptococcal infection to be relevant in all 3. One of the 15 patients with cutaneous polyarteritis nodosa (age range at onset 18-61 years) 
described by Borrie ${ }^{1}$ did have a raised ASO titre and another had exacerbations after tonsillitis. Our patient had shown a raised ASO titre on many occasions. However, she had had neither a sore throat before admission nor a history of sore throat, and repeated throat swabs were negative. She did complain of a sore throat 9 days after admission (20 June 1976) when slight throat inflammation was present and again in mid-November 1976, although at that time nothing abnormal was visible on examination.

Relapse may occur at some time in the future but if it does, there should be spontaneous resolution. It is of course possible but unlikely that she could develop the systemic disease later.

I thank Dr C S Smith and Dr Elizabeth Poskitt who were in charge of this case.

This child was presented (slides and discussion only) at the Section of Dermatology Meeting at the Royal Society of Medicine, London, in December 1976.

\section{References}

1 Borrie P. Cutaneous polyarteritis nodosa. Br J Dermatol 1972; 87: 87-95.

2 Verbov J, Stansfeld A G. Cutaneous polyarteritis nodosa and Crohn's disease. Trans St John's Hosp Dermatol Soc 1972; 58: 261-8.

3 Golding D N. Polyarteritis presenting with leg pains. $\mathrm{Br}$ Med J 1970; i: 277-8.

4 Ryan T J. Microvascular injury. Philadelphia: Saunders, 1976 ; 14-16, 308-12.

5 Anonymous. Cutaneous polyarteritis. $\mathrm{Br}$ Med J 1973; i: 6.

- Diaz-Perez J L, Winkelmann R K. Cutaneous periarteritis nodosa. Arch Dermatol 1974; 110: 407-14.

7 Reimold E W, Weinberg A G, Fink C W, Battles N B. Polyarteritis in children. Am J Dis Child 1976; 130: 534-41.

8 Bradford W D, Cook C D, Vawter G F. Livedo reticularis: a form of allergic vasculitis. $J$ Pediatr 1962; 60: 266-76.

Correspondence to Dr Julian Verbov, Royal Liverpool Children's Hospital, Liverpool L7 7DG.

\title{
Successful pregnancy in transfusion-dependent thalassaemia
}

\author{
R M THOMAS AND A E SKALICKA
}

Department of Paediatrics, Whittington Hospital, London

SUMMARY Successful pregnancy in a transfusiondependent thalassaemic patient receiving subcutaneous desferrioxamine is reported. This is the first such case to be described.

Endocrine impairment is well recorded in transfusion-dependent $\beta$-thalassaemia major, and puberty is nearly always delayed. ${ }^{1}$ This is thought to be due to gonadal or pituitary failure caused by iron deposition, although defective hypothalamic maturation has also been suggested. ${ }^{2}$ Endocrinopathy in nontransfusion-dependent $\beta$-thalassaemia intermedia is also well described, although it is less common than in thalassaemia major, and the presumed mechanism is increased gastrointestinal iron absorption or hypoxaemia, or both of these.

The beneficial effect of a high-transfusion regimen and chelation on the marrow hyperplasia, endocrine function, and growth velocity, and perhaps on the onset of puberty in this patient, has been described. ${ }^{3}$ Due to her irregular menses, pregnancy was not diagnosed until 14 weeks' gestation and she continued to administer her daily 12-hourly infusion of subcutaneous desferrioxamine during the first 16 weeks of pregnancy.

\section{Case reports}

The mother. She was the second child of Greek Cypriot parents, and was born in October 1960. A diagnosis of $\beta$-thalassaemia intermedia was made at age 13 months when haemoglobin $(\mathrm{Hb})$ was found to be $6.9 \mathrm{~g} / \mathrm{dl}$ after a traumatic fracture of her arm. HbF level was $32 \%$. With folic acid supplementation, $\mathrm{Hb}$ remained stable until age $3 \frac{1}{2}$ years when, with $\mathrm{Hb} 5 \mathrm{~g} / \mathrm{dl}$, she sustained a fracture of the left arm and right leg. At that time, splenectomy was performed because of hypersplenism ( 9 $\mathrm{cm}$ below costal margin).

Until age 12 years, her $\mathrm{Hb}$ level remained between 7 and $8 \mathrm{~g} / \mathrm{dl}$ without transfusion, but her growth velocity was poor (height $6 \mathrm{~cm},<3 \mathrm{rd}$ centile at age $12 \frac{1}{2}$ years) and she developed pronounced 'thalassaemic facies'. Because of conductive deafness and 'chronic serous otitis media', myringotomy was performed and showed the presence of bone marrow in the middle ear. She showed no sign of puberty 